\title{
An Efficient Technique for the Captive Breeding of an Endangered Freshwater Fish Salaria fluviatilis (Pisces: Blenniidae), with a Description of Its Ontogeny
}

\author{
FÁTIMA GIL \\ Aquário Vasco da Gama, R. Direita, Dafundo, P-1495 Lisboa Portugal \\ Cláudia Faria ${ }^{1}$ and Vítor Carvalho Almada \\ Unidade de Investigação em Eco-Etologia, Instituto Superior de Psicologia Aplicada, \\ R. Jardim do Tabaco 34, P-1149-041 Lisboa Portugal
}

\begin{abstract}
Salaria fluviatilis is one of the few freshwater members of the family Blenniidae and occurs around the Mediterranean Basin. This species is vulnerable or endangered in most countries where it occurs. Thus, information on its developmental biology and the establishment of methods for ex situ reproduction of highly endangered populations, to preserve them until natural habitats are restored, are much needed. A technique for the culture of this endangered species in controlled conditions is presented, together with the description of the full developmental sequence, from egg to adult. The use of the rotifer Brachionus calyciflorus at the onset of exogenous feeding proved to be an efficient way to allow larvae to reach the size when they can feed upon Artemia nauplii. Embryonic development lasted 12-14 d at 20-21 C. Newly hatched larvae measured $5.1 \mathrm{~mm}$ total length (TL). The mouth and anus were opened; the eyes were pigmented; there were almost no yolk; and the pectoral fins were small and unpigmented. Most larvae settled at 13.0-14.0 mm TL (27-31 d after hatching) and showed full juvenile pigmentation patterns at $27.0-28.0 \mathrm{~mm}$ TL (83 d after hatching). The larvae of this species showed agonistic behaviors once they began to settle.
\end{abstract}

Salaria fluviatilis (Asso 1801) is a freshwater member of the blenniid family that lives in rivers and lakes in the Mediterranean Sea basin and also in Portugal (Oliveira et al. 1992; Crivelli 1996). Although there are many studies about the ecology of this species (e.g., Freeman et al. 1990; Côté et al. 1999; Vinyoles et al. 1999, 2002), there is little information about its developmental biology. For the Iberian Peninsula, Vinyoles and De Sostoa (2007) described the life-history traits of this species. Sexual maturity is attained during their first year of life and females spawn multiple times during the breeding season. The breeding period is from May/June to August (Vinyoles and De Sostoa 2007). The demersal eggs are individually attached to the underside of a rock, or other

${ }^{1}$ Corresponding author. protected substratum, and formed single layered patches. They are guarded and aerated by the male until hatching. Typically, several females spawn in the same nest so that at a given time each male is guarding eggs at several developmental stages (Wickler 1957). S. fluviatilis is classified as vulnerable or endangered in the majority of the countries where it occurs (see Vinyoles and De Sostoa 2007). It is listed in the Appendix III of the Berne Convention, in the Appendix II of the Habitats Directive and is listed as Endangered in the Portuguese and the Spanish Vertebrate Red Data Books (SNPRCN 1992; Doadrio 2002), because of habitat loss, water pollution, the introduction of exotic species, and excessive water extraction (Elvira 1995; Collares-Pereira et al. 2000; Hernández et al. 2000). There is an urgent need to design and implement effective management and conservation measures to recover this endangered 
freshwater species. The information concerning its developmental biology is of much need to allow captive breeding when necessary for the recovery of natural populations. A major problem in rearing this species is that, in line with its origin from marine ancestors, S. fluviatilis retains a planktonic larval phase, which makes the techniques commonly used to rear most freshwater fishes unsuitable. In this article, a technique for the culture of S. fluviatilis in captivity is presented, together with the description of the full developmental sequence of this species, from egg to adult.

\section{Material and Methods}

Eggs and larvae were obtained from a captive group of 11 fish (5 males and 6 females), maintained in captivity since March 2007 at a public aquarium, Aquario Vasco da Gama (Lisbon). This stock was kindly provided by Professor Eduardo Barata (University of Algarve), and had been collected $3 \mathrm{yr}$ before at Laguna Bañoles (Cataluna, Spain). The 600 L tank (200 $\times 50 \times 60 \mathrm{~cm}$ ) was illuminated with a fluorescent light $(60 \mathrm{~W})$ from 0900 to $2100 \mathrm{~h}$. Both mechanical (powerhead with cartridge attachment; $1500 \mathrm{~L} / \mathrm{h}$ ) and biological (undergravel filter with airlifts) filters were used. In addition, one-third of the tank water was changed once a week (water quality parameters: $\mathrm{NH}_{4}^{+}=$ $0.013 \mathrm{mg} / \mathrm{L}$, range: $0.002-0.031 \mathrm{mg} / \mathrm{L}, n=5$; $\mathrm{pH}=8.05$, range: $7.85-8.20, \mathrm{n}=5$; dissolved oxygen $=5.44 \mathrm{mg} / \mathrm{L}$, range: $5.10-5.90 \mathrm{mg} / \mathrm{L}$, $n=5)$. The bottom of the tank was covered with a sand layer and several flat stones were provided as shelter and breeding sites. Temperature varied between 20 and $23 \mathrm{C}$. The adults were fed ad libitum once a day with chopped mussel and blood worm larvae.

The complete sequence of embryonic development was based on one batch spawned under a flat stone on April 17, 2007 (average temperature $=21 \mathrm{C}, \mathrm{SD}=0.74$, range: $20-21 \mathrm{C}$, $n=14$ ). A sample of eggs was removed daily from the stone guarded by the male, by aspiration with a long pipette. The eggs were observed under a Nikon Stereomicroscope, photographed by a Moticam 2300 Digital Camera and preserved in buffered $5 \%$ formalin. The egg capsules were opened and the embryos were distended to allow more detailed observations.

Full larval development was described from two other batches that hatched on June 12, 2007 (water temperature $=21 \mathrm{C}$ ) and July 16, 2007 (water temperature $=22 \mathrm{C}$ ). The rearing procedure was run twice. Upon hatching, the planktonic larvae were collected with a small glass and individually transferred to the rearing tanks. Each rearing tank was stocked with about 400 newly hatched larvae. These were $30 \mathrm{~L}$ glass tanks $(40 \times 30 \times 25 \mathrm{~cm})$, and each were illuminated with a fluorescent light (18 W) $24 \mathrm{~h}$ per day (the light was $4 \mathrm{~cm}$ above the tank cover). All the tank walls, except the one in the front, were painted black. A constant flow of water (2 L per hour) was maintained. Larvae were fed three times a day with a mixture of small size freshwater rotifers, Brachionus calyciflorus, and algae, Scenedesmus sp. (10 mL), maintaining a concentration of 4-8 rotifers $/ \mathrm{mL}$ in the rearing tank. The third meal, which was delivered during the night, was dispensed by a dripping system to ensure a gradual delivery. After Day 37 , these mixtures were enriched with decapsulated eggs of Artemia sp, with $0.2 \mathrm{~mm}$ width (20 mg each time) (Brine Shrimp Direct). After Day 49, they were also fed with blood worm larvae (700 mg each time). After Day 64, they were fed three times a day with decapsulated Artemia eggs and two times a day with a mixture of blood worm larvae and chopped mussel (see Table 1). After Day 96, the diet was

TABLE 1. Feeding regime of the rearing tanks.

\begin{tabular}{|c|c|c|c|c|c|}
\hline & Alga & Rotifers & $\begin{array}{l}\text { Decapsulated } \\
\text { Artemia eggs }\end{array}$ & $\begin{array}{l}\text { Blood worm } \\
\text { larvae }\end{array}$ & $\begin{array}{c}\text { Chopped } \\
\text { mussel }\end{array}$ \\
\hline Item concentration & - & $4-5$ rotifers $/ \mathrm{mL}$ & $20 \mathrm{mg}$ & $700 \mathrm{mg}$ & $100 \mathrm{mg}$ \\
\hline Feeding schedule & Three times a day & Three times a day & Three times a day & Two times a day & Two times a day \\
\hline Feeding days & D1-D63 & D1-D63 & D37-D95 & D49-D95 & D64-D95 \\
\hline
\end{tabular}


replaced by that of the adults. The reared tanks were cleaned daily, before the first feeding, by aspiration of the bottom with an acrylic tube of $4 \mathrm{~mm}$ of internal section. Once a week, the walls of the tank were cleaned with a razor blade to remove the algal film.

The algal stock was isolated and regularly cultured in Aquário Vasco da Gama. Conical $14 \mathrm{~L}$ acrylic tanks were employed. Each culture was started with $5 \mathrm{~L}$ of a pre-existing culture and $9 \mathrm{~L}$ of tap water, which was allowed to rest for at least $2 \mathrm{~d}$. Fourteen milliliters of Conway medium were added to the tank as fertilizer. Temperature was kept at 19-22 C and the tanks were illuminated $22 \mathrm{~h}$ per day with fluorescent lights $(40 \mathrm{~W})$. Algal concentration was not controlled, but each culture was considered ready for use after about $8 \mathrm{~d}$, if the water displayed an intense green color. The same tanks, and light regime, were used for the rotifer cultures. In this case, the temperature was kept at 22-24 C. Each day, 2 L of rotifer culture was removed and sieved, with a net of $45 \mu \mathrm{m}$ mesh. This volume was replaced by an equivalent volume of the algal culture described above. Rotifer concentration ranged between 5 and 86 rotifers/mL.

An unexpected mortality was detected when the fish were about 3 wk old and saltwater was added to the water and salinity was kept at $2.2 \%$ from Day 21 to Day 114. Larvae were collected daily, anesthetized using Ethylene Glycol Monophenyl Ether Merck (less than $1 \mathrm{~mL}$ ) and photographed until metamorphosis. After metamorphosis, juveniles were kept in the same tanks but light intensity was reduced during the night, with a semi-opaque screen, and stones were placed on the bottom to provide shelter. All larval measurements correspond to total lengths (TLs).

\section{Results}

Captive males guarded egg batches from April to September (two to three males at each time). All adults survived. In each nest, there were simultaneously eggs at several developmental stages. Recently laid eggs were whitish, and in subsequent days they became more
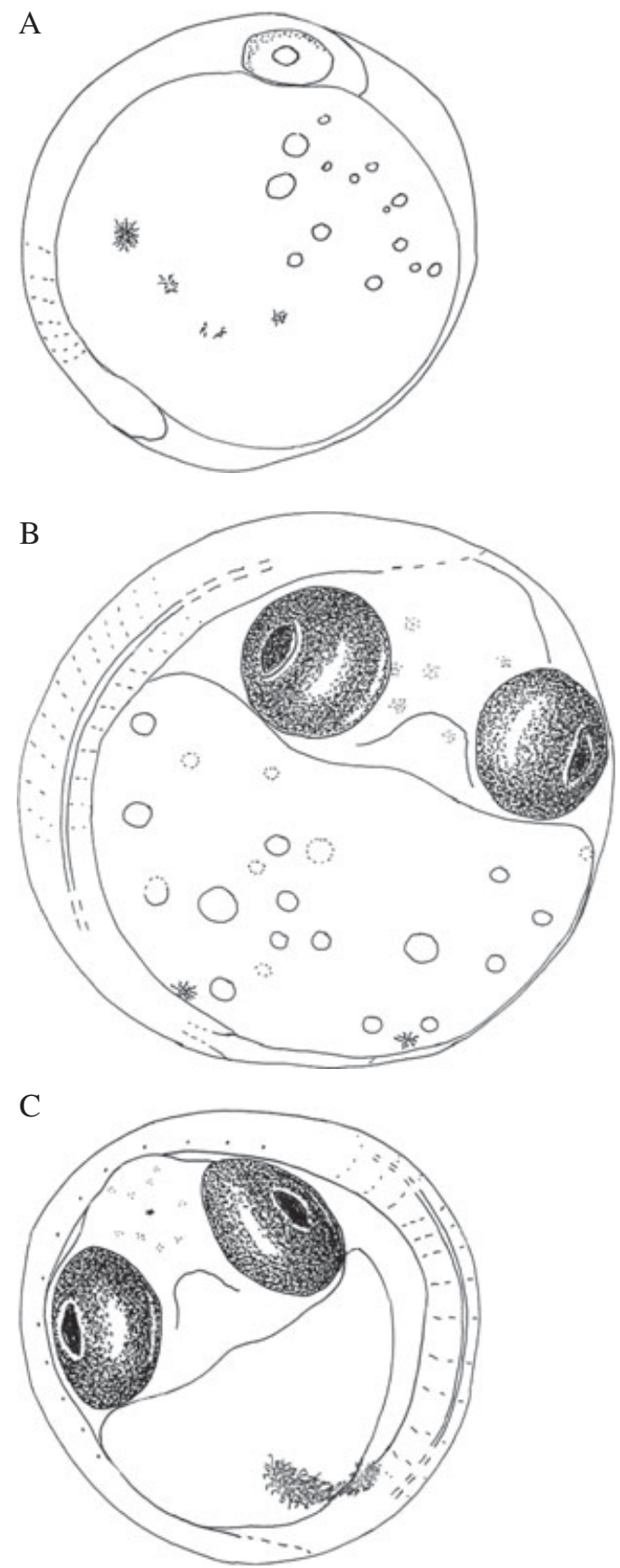

FIGURE 1. Eggs collected at different developmental stages: (A) Day 3: embryo differentiation; (B) Day 8: embryo with mouth differentiated; (C) Day 12: embryo just prior to hatching.

brownish. They were semi-spherical (Fig. 1) and had a flat attachment disk. The major axis was $1.2 \mathrm{~mm}(\mathrm{SD}=0.05$, range: $1.1-1.2 \mathrm{~mm}$, 
TABLE 2. Ontogenetic events of embryonic development of Salaria fluviatilis in order of first appearance (days after hatching): (1) embryo recognizable; (2) cephalic and caudal dilatation; (3) eye lens; (4) brain; (5) notochord differentiation; (6) myomeres; (7) beginning of pigmented eyes; (8) tail bud free of the yolk; (9) auditory vesicules; (10) gut differentiation; (11) median finfold; (12) otoliths; (13) anus visible but closed; (14) pectoral fin buds; (15) mouth differentiation; (16) mouth visible but closed; (17) anus opened; (18) opercula differentiation; (19) mouth opened; (20) hatching glands; (21) opercula opened; (22) hatching. Temperature range: 20.00-21.00 C.

\begin{tabular}{lrrrrrrrrrrrrrrrrrrrrrr}
\hline Events & 1 & 2 & 3 & 4 & 5 & 6 & 7 & 8 & 9 & 10 & 11 & 12 & 13 & 14 & 15 & 16 & 17 & 18 & 19 & 20 & 21 & 22 \\
Days & 2 & 2 & 3 & 3 & 3 & 3 & 3 & 3 & 3 & 3 & 5 & 5 & 5 & 6 & 7 & 8 & 10 & 11 & 11 & 12 & 12 & 13 \\
\hline
\end{tabular}

$n=10)$ and the minor axis was $0.7 \mathrm{~mm}(\mathrm{SD}=$ 0.03, range: $0.7-0.8 \mathrm{~mm}, n=10$ ). Embryonic development lasted $12-14 \mathrm{~d}$ at $20-21 \mathrm{C}$.

The main ontogenetic events of embryonic and larval development are shown in Tables 2 and 3 , respectively.

Newly-hatched larvae (Fig. 2A) measured $5.1 \mathrm{~mm}$ TL ( $\mathrm{SD}=0.07$, range: $5.0-5.1 \mathrm{~mm}$, $n=10$ ). The anus and mouth were open, with formed lips and differentiated jaws. The yolk was almost fully absorbed. The liver was developed and the eyes were fully pigmented. The opercula were open, and the sagittae and lapilli otoliths were visible. The pectoral fins were small and rounded, without any rays or pigmentation.

Newly-hatched larvae had a heavy peritoneal pigmentation. Ventrally there was a melanophore near the anus and a series of melanophores at the posterior half of the larvae. Dorsally, there were many melanophores on the head and internally at the otic vesicules. There was also an internal row of melanophores from behind the eyes to the gut. The base of the pectoral fins presented one ramified melanophore. There was also some diffuse yellowish pigmentation all over the head and at the base of the pectoral fins.

The pigmentation pattern was maintained during development, with an increase in the number and intensity of melanophores at the ventral row, in front of the liver, and at the cephalic region and opercula (see Table 3 ).

The juvenile pigmentation (Fig. 2D) appeared at 26.0-28.0 mm TL (83 d after hatching). The head, lips, opercula, anterior part of the body, and the base of the pectoral fins were heavily pigmented. There was a dark band that extended from the upper lip to the lateral side of the head above the eye. There were dark spots along the dorsal and ventral mid-line. The dorsal, caudal, and the posterior anal fin rays were pigmented. There were also melanophores on the bases of the caudal and anal fins. On the pectoral fins, there was a transverse band of melanophores in the middle of the fin and there were melanophores along the lower rays.

Newly-hatched larvae presented a relatively small preanal length (29\% of SL). At $7.0 \mathrm{~mm}$ (5 d after hatching), the larvae possessed two to four preopercular spines. At $11.0 \mathrm{~mm}$ TL (18-20 d after hatching), the total number of vertebrae was 36-37, excluding the urostyle (10 preanal vertebrae) and all fin rays were present $(D=\mathrm{XII}-\mathrm{XIII}+16-20$; $A=\mathrm{II}+17-21 ; V=\mathrm{I}+3 ; P=12-14)$. At 8.6-9.0 $\mathrm{mm}$ TL (12 $\mathrm{d}$ after hatching), the notochord flexion was completed (Fig. 2B).

The change to a benthic mode of life was gradual. At $11.2 \mathrm{~mm}$ TL (20 d after hatching), fish began to contact the aquarium bottom. Gradually they spent longer times at the bottom, until they permanently settled. Most fish settled at $13.0-14.0 \mathrm{~mm}$ TL (27-31 d after hatching), before acquiring juvenile pigmentation (Fig. 2C). At this time, they began to show agonistic behaviors, like charging (one fish in front of another bends its body in an "S" posture and charges, a movement similar to the one used to capture prey items), butting on the caudal fin of another fish, chasing, and fleeing. Fish measured 22.0-23.0 mm TL $(n=26) 48$ $\mathrm{d}$ after hatching, 28.0-29.0 $\mathrm{mm}$ TL $(n=25)$ $82 \mathrm{~d}$ after hatching, and $46.0-48.0 \mathrm{~mm}$ TL ( $n=25) 210 \mathrm{~d}$ after hatching. Some fish began to show the crest on the head, typical of males, $86 \mathrm{~d}$ after hatching, and $112 \mathrm{~d}$ after hatching all males had already a conspicuous crest. As the adults were kept in groups and the eggs were guarded by the males under stones, estimation 
of egg mortality was not attempted to avoid disturbing the guarding fish. During the $31 \mathrm{~d}$ of larval development, mortality was about $85 \%$ in each tank. Juvenile mortality was $20 \%$. A total of 48 juveniles were still alive at the end of February 2008.

\section{Discussion}

The developmental sequence described in this study agrees in general with those described for other blenniid species and may be useful to identify larvae collected in the plankton (e.g., Olivar 1986; Sabates 1994; Faria et al. 2002, 2005, 2006). Although S. fluviatilis presents a number of traits that could be advantageous to survive in unstable environments, such as a long spawning period, multiple spawnings, and parental care of the eggs by the males (Vinyoles and De Sostoa 2007), it seems to be vulnerable to many anthropogenic disturbances that affect Mediterranean type streams (Elvira 1995; Collares-Pereira et al. 2000; Hernández et al. 2000). When compared with other fish that inhabit the same environments, namely cyprinids (e.g., Carvalho et al. 2003), the development of $S$. fluviatilis is remarkable for the presence of almost a month of planktonic larval life, a feature probably inherited from its marine ancestors (most blenniids are marine) (Nelson 2006). In fluvial systems, planktonic larvae must run a high risk of downstream drifting, which may drive them to unfavorable habitats. Moreover, many freshwater systems have reduced depths. In these circumstances, larvae are at short distances both from the surface and the bottom, a condition which could increase the spectrum of potential predators. Fischer and Kummer (2000) suggested that one of the key issues to the conservation of this endangered species is the preservation of intact flow conditions in the rivers. This may be important to avoid siltation of the nests, but as suggested by the present results, must be sufficiently weak to avoid downstream transport of the larvae. The increasing unpredictability of flow regimes in Mediterranean rivers, apparently associated with the current climate change, is causing severe summer droughts, which are aggravated 


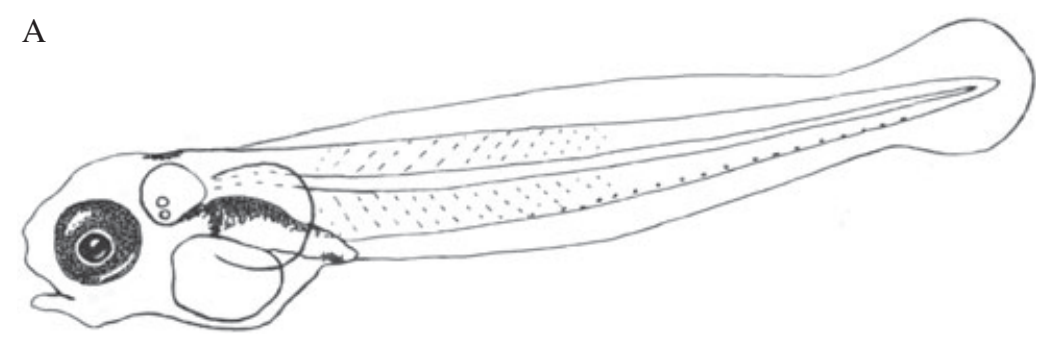

B
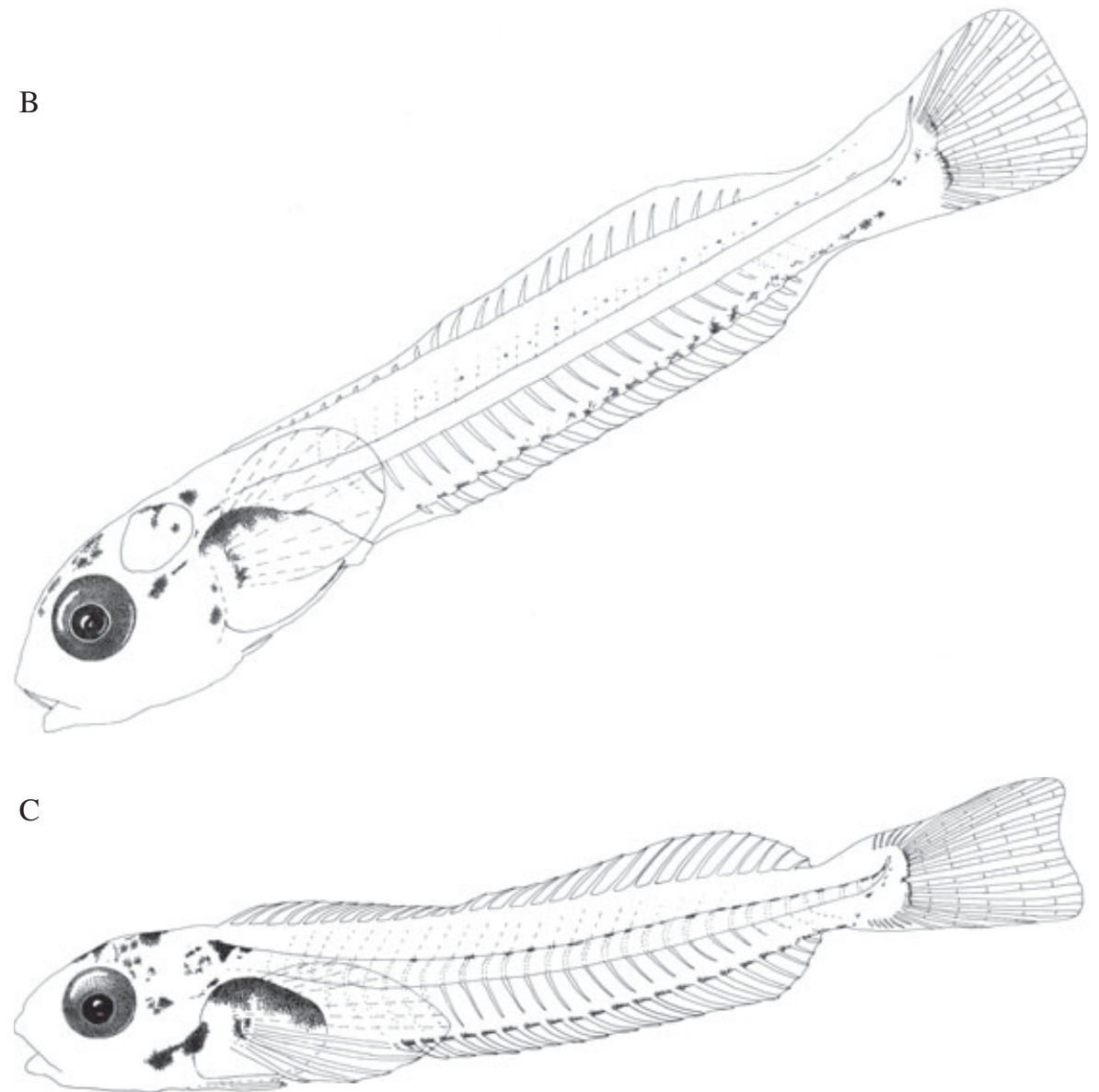

$\mathrm{D}$

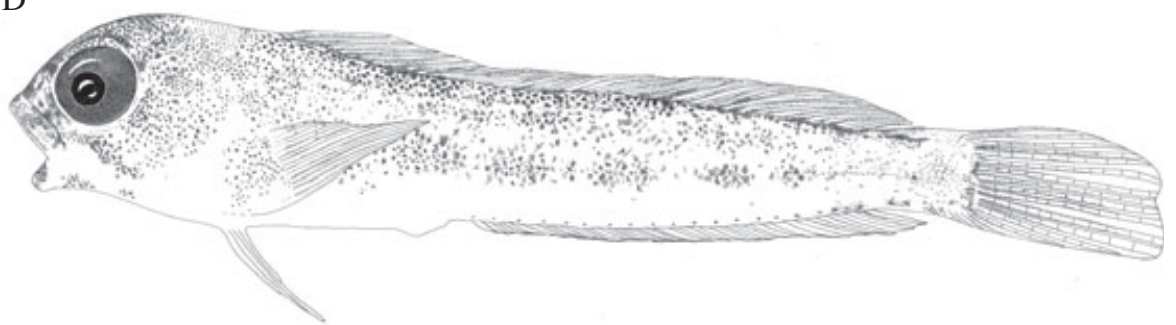

FiguRE 2. Larvae collected at different developmental stages: (A) Day 1: newly hatched larvae (5.1 mm TL); (B) Day 15: $9.2 \mathrm{~mm} \mathrm{TL;} \mathrm{(C)} \mathrm{Day} \mathrm{27:} 13.2 \mathrm{~mm}$ TL; (D) Day 83: juvenile (28.0 mm TL). 
in many places by water extraction. These droughts and flooding at unusual periods may be a major risk for this species.

The duration of the larval planktonic stage also means that during their first month of life, fish are unable to control their movements to reach benthic prey, and thus depend on zooplankton of suitable size in the water column. On the other hand, when they hatch the larvae are too small to feed upon young daphnia or artemia nauplii. We believe that a key to the success of this culture experiment was the use of a stock of small-sized freshwater rotifers during the first $2 \mathrm{wk}$ of larval growth. Although microalgae were added to the rearing tanks with the aim to keep the nutritional value of the rotifers, they were observed in the guts of larvae during the first week in the rearing tanks, so we cannot rule out the possibility that the algae were also been used as food by the fish. Future studies, aimed to clarify this question, could help to optimize the diet for rearing the larvae of this endangered fish.

Although larval mortality was high, it is important to remember that males of this species, which are of small size, can guard thousands of eggs in a season (Wickler 1957). Moreover, if a sufficient number of nests is provided, a considerable number of guarding males can be kept per square meter (three males with nests per square meter in our setup). Thus, although we consider that additional studies are needed to reduce larval mortality, the present protocol is sufficient to produce thousands of juveniles in a season, even if space for broodstock is limited to a few square meters of tank area.

\section{Acknowledgments}

This study was supported by Fundação para a Ciência e Tecnologia (FCT) as part of Pluriannual Program (UI\&D 331/94, partially FEDER funded) and by FCT and FEDER as part of the project POCTI/BSE/46825/2002. C. F. was also supported by a grant from FCT (SFRH/BPD/26939/2006). We would like to thank the technicians of Aquário Vasco da Gama for the help in tank maintenance, Rita
Lourenço for the illustrations and L-IPIMAR for the supply of a freshwater rotifer sample and maintenance technique.

\section{Literature Cited}

Carvalho, V., J. I. Robalo, and V. C. Almada. 2003. A description of the reproductive behaviour of the endangered Iberian cyprinid Chondrostoma lusitanicum Collares-Pereira 1980 in captivity. Etología 10:23-25.

Collares-Pereira, M. J., I. G. Cowx, F. Ribeiro, J. Á. Rodrigues, and L. Rogado. 2000. Threats imposed by water resource development schemes on the conservation of endangered fish species in the Guadiana River Basin in Portugal. Fisheries Management and Ecology 7:167-178. DOI: 10/1046/j.1365-2400.2000. 00202.x.

Côté, I., D. Vinyoles, J. D. Reynolds, I. Doadrio, and A. Perdices. 1999. Potential impacts of gravel extraction on Spanish populations of river blennies Salaria fluviatilis (Pisces, Blenniidae). Biological Conservation 87:359-367.

Crivelli, A. J. 1996. The freshwater fish endemic to the Mediterranean region. An action plan for their conservation. Tour du Valat Publication, Carmargue, France.

Doadrio, I. 2002. Atlas y libro rojo de los peces continentales de España. Madrid: Dirección General de Conservación de la Naturaleza and Museu Nacional de Ciencias Naturales.

Elvira, B. 1995. Native and exotic freshwater fishes in Spain river basins. Freshwater Biology 33:103-108.

Faria, C., R. Borges, F. Gil, V. C. Almada, and E. J. Gonçalves. 2002. Embryonic and larval development of Lipophrys pholis (Pisces: Blenniidae). Sciencia Marina 66:21-26.

Faria, C., F. Gil, and V. C. Almada. 2005. Ontogenetic development of Lipophrys trigloides (Pisces: Blenniidae), with some notes on the spawning behaviour. Journal of the Marine Biological Association of United Kingdom 85:185-188.

Faria, C., F. Gil, and V. C. Almada. 2006. Ontogenetic development of Parablennius pilicornis (Pisces: Blenniidae) in controlled conditions. Sciencia Marina 70(4):667-671

Fischer, R. and H. Kummer. 2000. Effects of residual flow and habitat fragmentation on distribution and movement of bullhead (Cotus gobio L.) in an alpine stream. Hydrobiologia 422:305-317. DOI: 10.1023/A: 1017083714513.

Freeman, M. C., D. Vinolas, G. D. Grossman, and A. De Sostoa. 1990. Microhabitat use by Blennius fluviatilis in the Rio Matarrana, Spain. Freshwater Biology 24:335-345.

Hernández, R., R. T. Lacomba, Y. N. Uviñas, and R. Oltra. 2000. Distribution pattern of river blennies in the Júcar river basin (eastern Spain). Journal of 
Fish Biology 57:250-254. DOI: 10.1111/j.1095-8649. 2000.tb00790.x.

Nelson, J. S. 2006. Fishes of the world, 4th edition. JohnWiley and Sons, New York, New York, USA.

Olivar, M.-P. 1986. Development and distribution of Parablennius pilicornis (Cuvier) larvae (Teleostei: Blenniidae) off Namibia. South African Journal of Marine Science 4:193-201.

Oliveira, R. F., V. C. Almada, A. J. Almeida, R. S. Santos, and E. J. Gonçalves. 1992 A checklist of the blennioid fishes (Teleostei, Blennioidei) occurring in Portuguese waters. Arquipélago. Ciencias da Natureza 10:23-37.

Sabates, A. 1994. Larval development of three blenniid species Aidablennius sphinx, Coryphoblennius galerita and Lipophrys canevai (Pisces: Blenniidae: Blenniini) in the Western Mediterranean. Journal of Zoology of London 234:89-103.

SNPRCN (Serviço Nacional de Parques, Reservas e Conservação da Natureza). 1992. Livro vermelho dos vertebrados de Portugal. Vol II. Peixes dulciaquícolas e migradores. Secretaria de Estado do Ambiente e Defesa do Consumidor, Lisboa.

Vinyoles, D. and A. De Sostoa. 2007. Life-history traits of the endangered river blenny Salaria fluviatilis (Asso) and their implications for conservation. Journal of Fish Biology 70:1088-1108.

Vinyoles, D., I. M. Côté, and A. De Sostoa. 1999. Egg cannibalism in river blennies: the role of natural prey availability. Journal of Fish Biology 55:1223-1232. DOI: 10.111/J.1095-8649.1999.tb02072.x.

Vinyoles, D., I. M. Côté, and A. De Sostoa. 2002. Nest orientation patterns in Salaria fluviatilis. Journal of Fish Biology 61:405-416. DOI: 10.1111/j.1095-8649. 2002.tb01573.x.

Wickler, W. 1957. Vergleichende Verhaltensstudien an Grundfischen. I. Beiträge zur biologie, besonders zur ethologie von Blennius fluviatilis Asso im vergleich zu einigen anderen bodenfischen. Zeitschrift für Tierpsychologie 14:393-428. 